\title{
ABDOMINAL COMPARTMENT SYNDROME DUE TO WARFARIN-RELATED RETROPERITONEAL HEMATOMA
}

\author{
Mônica Mourthé de Alvim Andrade, Marcelo Batista Pimenta, Bruno de Freitas Belezia, Rafael Lodi Xavier, Augusto \\ Motta Neiva
}

\section{INTRODUCTION}

Retroperitoneal bleeding is a rare complication of anticoagulant therapy. The clinical consequences depend on the rate of blood loss and on the total amount of blood that is lost into the retroperitoneum. ${ }^{1}$ Once diagnosed, this condition requires immediate suspension of the anticoagulant, correction of the coagulation disorders and fluid restoration. ${ }^{1,2}$

\section{CASE DESCRIPTION}

A 49-year-old female patient was admitted to hospital complaining of progressive and severe abdominal pain for the past 3 days. She had been taking warfarin due to a prior diagnosis of deep venous trombosis of the lower extremities. Upon admission her abdomen was mildly distended, her intravesical pressure (IVP) was $45 \mathrm{~cm} \mathrm{H}_{2} \mathrm{O}$ and her blood pressure (initially $70 / 40 \mathrm{mmHg}$ ) rose to $110 / 80$ $\mathrm{mmHg}$ after rapid administration of $1000 \mathrm{ml}$ of saline solution. The blood count ordered upon her arrival showed a hemoglobin level of $4.1 \mathrm{~g} / \mathrm{d}$, and an international normalized ratio (INR) of 4.4. CT of the abdomen and pelvis showed a large retroperitoneal and pelvic hematoma [figure 1]. Initially, a conservative approach was adopted: the patient received $1200 \mathrm{ml}$ of packed red cells (PRC), $1000 \mathrm{ml}$ of fresh frozen plasma and $3500 \mathrm{ml}$ of crystaloid solution. However, after the first 12 hours of observation she developed oliguria, seizures, shock and respiratory failure. Serial physical examinations revealed marked abdominal distension and IVP rose to $60 \mathrm{~cm} \mathrm{H}_{2} \mathrm{O}$. The clinical picture resembled abdominal compartment syndrome (ACS) and a decision for decompressive laparotomy was made. As soon as the abdominal cavity was opened the ventilatory and hemodynamic parameters improved significantly, which

Hospital Municipal Odilon Behrens - Belo Horizonte, MG/ Brazil Email: monicamourtheaa@yahoo.com.br confirmed ACS. A large retroperitoneal hematoma was seen but not explored, since the purpose of the procedure was only for decompression. A laparostomy with a Bogotá bag was performed [figure 2] and the patient was sent to the intensive care unit where she stayed for 12 days, with progressive improvement in hemodynamic and ventilatory parameters. During this period she received another $600 \mathrm{ml}$ of PRC and by the $10^{\text {th }}$ day all coagulation parameters were in the normal range. She then underwent serial closure of the laparostomy according to our service protocol and by the end of 29 days the abdomen was totally closed. A duplex scan confirming deep venous thrombosis of the left lower extremity was ordered after internal medicine and vascular surgery consultations. Because the patient had not had an episode of pulmonary embolism and because inadequate control of anticoagulation was considered to be the probable cause of the retroperitoneal hematoma, systemic anticoagulation with heparin was reintroduced. As an outpatient she was kept on warfarin for another 6 months without any further bleeding complications.

\section{DISCUSSION}

Oral anticoagulants have had an expanding role in cardiovascular and thrombotic disorders. Major indications for warfarin use are nonvalvular atrial fibrillation, venous thrombosis, rheumatic heart disease, mechanical heart valve prosthesis, and pulmonary, cerebral or systemic embolism..$^{3-5}$ Warfarin therapy is associated with a variety of hemorrhagic complications that are usually associated with inadequate control of anticoagulation. ${ }^{2}$ This is probably what happened to the patient reported above, since her INR was 4.4. Spontaneous retroperitoneal hematomas are rare; Brathwaite $\mathrm{CE}$ et al. described only one case of a retroperitoneal hematoma out of 13 patients that required termination of anticoagulation due to hemorrhagic complications $^{6}$. Stephan D and colleagues evaluated 928 patients that were on chronic anticoagulation with warfarin in a retro- 


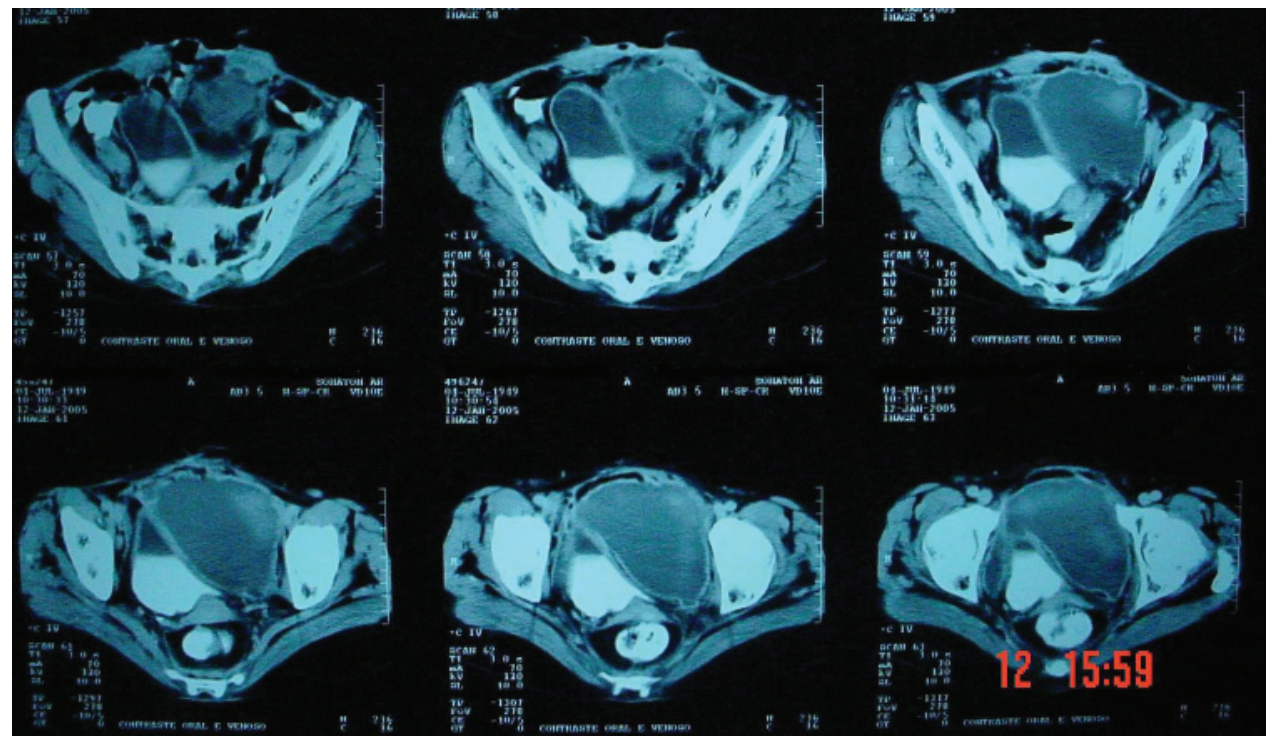

Figure 1 - Computed tomography showing a large retroperitoneal hematoma, shifting the rectum and bladder to the right.

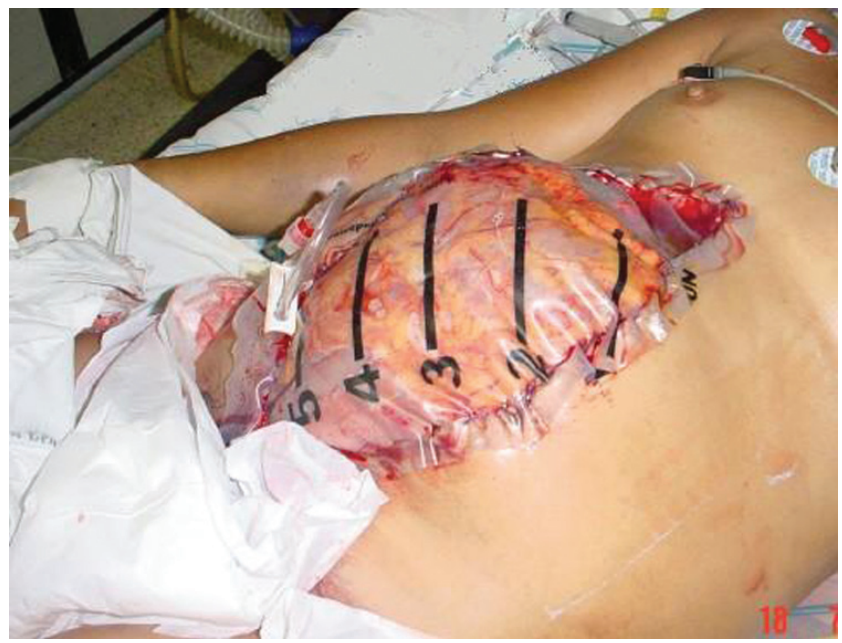

Figure 2 - Laparostomy

spective cohort study. They found an incidence of first bleeding episodes of 17.3 events/100 patient-years for minor bleeding, 7.5 events/100 patient-years for serious bleeding, 1.1 events/100 patient-years for life-threatening bleeding and 0.2 events/100 patient-years for fatal bleeding 5 . Four variables demonstrated an independent relation to the risk of a first episode of bleeding according to this study: mean prothrombin time ratio (PTR) of 2.0 or greater, short duration anticoagulation (during the first three months of anticoagulation therapy, the risk of bleeding is higher than after the forth month), high PTR variability and the presence of three or more comorbid conditions. ${ }^{5}$ Another study showed an incidence of major bleeding in patients treated with coumarin derivatives of 1.4 per 100 patient-years. $^{7}$

Abnormal and sudden increase in the volume of any component of the intra-peritoneal or extra-peritoneal spaces can cause intraperitoneal hypertension. ${ }^{8}$ When associated with organ dysfunction (elevated airway pressure, cardiac output reduction, and oliguria) it meets the criteria for ACS. ${ }^{9,10}$ This usually occurs when the intra-abdominal pressure, measured by IVP, is above $20-25 \mathrm{~cm} \mathrm{H}_{2} \mathrm{O} .{ }^{9,11}$ The volume increase is mainly due to abdominal trauma, but may also be caused by significant intra-abdominal bleeding or collections, retroperitoneal hematomas, difuse peritonitis, peritoneal edema due to vigorous volemic ressucitation, packing of the abdominal cavity (damage control), pancreatitis, pneumoperitoneum and neoplasms. ${ }^{11-13}$ Treatment consists of prompt surgical decompression and volemic resuscitation. ${ }^{8,10-14}$ The mortality rate varies from 29 to $62 \%$ and is usually due to multiple organ failure and sepsis. ${ }^{10,14,15}$

In regard to the case presented above, a nonoperative approach to a retroperitoneal hematoma was attempted first. However, after fluid and blood replacement, the patient presented with a full-blown clinical picture of ACS, which led to a straightforward decision for a laparostomy.

A review of the literature reveals little data regarding the duration of withholding warfarin, subsequent thromboembolic complications, and the risk of rebleeding on resumption of warfarin treatment in these patients. Ananthasubramaniam $\mathrm{K}$ et al. studied these considerations in patients with prosthetic heart valves hospitalized with a major bleeding event. The mean duration of warfarin withholding during hospitalization in their study was $15 \pm 4$ days and none of their patients received other antithrombotic therapies during hospitalization. All of their patients resumed warfarin therapy when they were deemed stable by their primary physicians and did not have any 
thromboembolic events or significant rebleeding episodes. ${ }^{16}$ Little data exist about recurrent bleeding after resumption of warfarin therapy, but it appears to be common within 5 months of the resumption of anticoagulation. Those whose first bleeding was from a gastrointestinal source are particularly at risk for a second event. ${ }^{5,16}$ Aggressive treatment of the bleeding source and the risk-benefit ratio of continued anticoagulation need to be considered. An alternative for these high risk rebleeding patients is early caval filter placement. $^{6}$

In conclusion, a large retroperitoneal hematoma is a severe and potentially fatal complication of anticoagulant therapy. Patients with this sort of complication require constant monitoring of hemodynamic and ventilatory parameters, diuresis and intravesical pressure, since they are at risk for developing ACS.

\section{REFERENCES}

1. Suárez G, Valera Z, Gómez MA, Docobo F, Alamo JM. Etiology and diagnosis of severe retroperitoneal hematoma: threrapeutic options and surgical indication. Cir Esp. 2005;78:328-330.

2. Andrews FJ. Retroperitoneal haematoma after paracetamol increased anticoagulation. Emerg Med J. 2002;19:84-85.

3. Chan TY, Miu KY. Hemorrhagic complications of anticoagulant therapy in Chinese patients. J Chin Med Assoc. 2004;67:55-62.

4. Fanikos J, Grasso-Correnti N, Shah R, Kucher N, Goldhaber SZ. Major Bleeding complications in a specialized anticoagulation service. Am J Cardiol. 2005;96:595-598.

5. Fihn SD, McDonell M, Martin D, Henikoff J, Vermes D, Kent D et al Risk Factors for complications of chronic anticoagulation: a multicenter study. Ann Intern Med. 1993;118:511-520.
6. Brathwait CE, Mure AJ, O’Malley KF, Spence RK, Ross, SE. Complications of anticoagulation for pulmonary embolism in low risk trauma patients. Chest. 1993;104:718-20.

7. Cannegleter SC, Rosendaal FR, Briet E. Thromboembolic and bleeding complications in patients with mechanical heart valve prostheses. Circulation. 1994;89:635-641.

8. Decker G. Abdominal compartment syndrome. J Chir. 2001;138:270276.

9. Sieh KM, Chu KM, Wong J. Intra-abdominal hypertension and abdominal compartment syndrome. Langenbecks Arch Surg. 2001;386:53-61.

10. Hunter JD, Damani Z. Intra-abdominal hypertension and the abdominal compartment syndrome. Anaesthesia. 2004;59:899-907. 
11. Wysocki A. Abdominal compartment syndrome: current view. Przegl Lek. 2001;58:463-465.

12. Majchrzak C. Abdominal compartment syndrome: a case review. Perianesth Nurs. 2002;17:413-417.

13. Walker J, Criddle LM. Pathophysiology and management of abdominal compartment syndrome. Am J Crit Care. 2003;12:367-710.

14. Moore AF, Hargest R, Martin M, Delicata RJ. Intra-abdominal hypertension and the abdominal compartment syndrome. Br J Surg. 2004;91:1102-1110.
15. Stagnitti F, Calderale SM, Priore F, Ribaldi S, Tiberi R, De Pascalis M et al. Abdominal compartment syndrome: patophysiologic and clinic remarks. G Chir. 2004;25:335-342.

16. Ananthasubramaniam K, Beattle JN, Rosman HS, Jayam V, Borzak S How Safety and for How Long Can Warfarin Therapy Be Withheld in Prosthetic Heart Valve Patients Hospitalized with a Major Hemorrhage? Chest. 2001;119:478-484. 